\title{
Trichogrammatoidea bactrae (Hymenoptera: Trichogrammatidae): A Potential Biocontrol Agent of Rice Leaf Folder
}

\author{
M.C.D. Perera, K.S. Hemachandra ${ }^{1 *}$ and U.G.A.I. Sirisena ${ }^{2}$ \\ Postgraduate Institute of Agriculture \\ University of Peradeniya \\ Sri Lanka
}

\begin{abstract}
Rice leaf folder, Cnaphalocrocis medinalis is a major pest, in many rice growing areas of Sri Lanka. Biological control of this pest is encouraged due to ill effects of insecticide application on rice ecosystem. Use of egg parasitoids is advantageous over larval and pupal parasitoids, as they could destroy pests at the egg stage. Trichogrammatoidea bactrae present in rice fields in Sri Lanka, is an egg parasitoid of rice leaf folder. This study was conducted to assess the potential of $\underline{T}$. bactrae as a biocontrol agent for the management

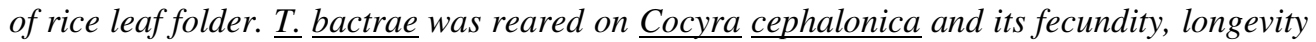
and parasitism were assessed. Acceptance of stored host eggs and parasitoid emergence from stored parasitized eggs were examined. Dispersal ability of parasitoid was also

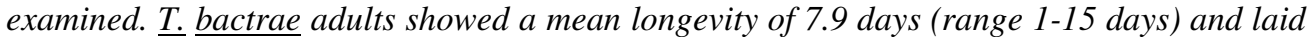
55 eggs / female during first 5 days; of which, $56 \%$ of eggs was laid on the first day. There was a significant reduction $(F=5.26 ; d f=14 ; 89 ; P<0.001)$ in parasitism, 66-35\%, with increasing number of generations on $\underline{C}$. cephalonica. Parasitism steadily decreased as the number of generations increased. Acceptance of $\underline{C}$. cephalonica eggs varied significantly with temperature $(F=187 d f=1 ; 126 P<0.001)$. Mean acceptance at 4 and $8{ }^{\circ} \mathrm{C}$ was 30 and $42 \%$ respectively. Acceptance also significantly varied with the duration stored ( $F=385$; $d f=6 ; 126 ; P<0.001)$. Parasitized eggs of $\underline{T}$. bactrae could be successfully stored under low temperature $\left(4{ }^{\circ} \mathrm{C}\right)$ up to $40 \mathrm{~d}$. Over $80 \%$ parasitism was achieved with 150 parasitoids released within $25 \mathrm{~cm}$ radius circle. Hence, $\underline{T}$. bactrae is a promising candidate to be promoted as a biocontrol agent of $\underline{C}$. $\underline{\text { medinalis. }}$.
\end{abstract}

Keywords: Dispersal, fecundity, longevity, parasitization, Trichogrammatoidea bactrae

\section{INTRODUCTION}

Rice leaf folder (RLF), Cnaphalocrocis medinalis (Guenee) (Lepidoptera: Pyralidae) is considered as one of the major rice leaf feeding insect in many parts of Sri Lanka (Nugaliyadde et al., 2000). RLF females lay eggs singly or in small clusters on the leaf blade of rice plants. After four days, egg hatch and larvae emerge (Ranasinghe, 1992). Damage due to defoliation caused by RLF larvae demands the implementation of control measures, usually application of insecticides. This practice adversely affects the colonizing natural enemies in rice ecosystems (Roger et al., 1991; Lawler, 2001). Natural enemy community in rice ecosystem has a greater impact on other pest species of rice as well (Barrion and Litsinger, 1994; Ooi and Shepard, 1994; Heong et al., 2005). Hence, use of non-chemical

1. Department of Agricultural Biology, Faculty of Agriculture, University of, Peradeniya, Sri Lanka

Department of Plant Sciences, Faculty of Agriculture, Rajarata University of Sri Lanka

Corresponding author: kshema@pdn.ac.lk 
strategies to manage RLF has been considered to enhance the colonization of natural enemy community in the rice ecosystem.

Of the non chemical strategies, biological control of RLF using egg parasitoids is the most promising. Use of larval and pupal parasitoids to manage rice leaf folder has practical limitations. RLF larvae have already damaged the rice foliage when larval parasitoids begin to destroy the larvae. In contrast, egg parasitoids destroy the RLF at the egg stage, prior to leaf damage by larvae. Trichogrammatoidea bactrae Nagaraja has been identified as a naturally occurring egg parasitoid that can be used against RLF (Hemachandra et al., 2014). The potential of this egg parasitoid in the control of RLF has not been properly investigated.

Success of a biocontrol programme depends much on the biology of the biocontrol agent and the convenience of rearing of the parasitoids on surrogate host eggs to produce adequate numbers for field release. Therefore, the objective of this study was to assess Trichogrammatoidea bactrae as a potential biocontrol agent. Its fecundity, longevity, dispersal ability of adults in searching of host eggs, effects of number of generations of parasitoids on parasitization capacity, acceptance of cold stored eggs for parasitization were investigated.

\section{METHODOLOGY}

This study was conducted based in the laboratories of the Department of Agricultural Biology, Faculty of Agriculture, University of Peradeniya from November, 2011 to 2013. The egg parasitoid, T. bactrae was reared on Cocyra cephalonica eggs to obtain parasitoids for experimentation adopting the rearing protocol of Nathan et al. (2006). C. cephalonica was reared on crushed corn as described by Sreekumar and Paul (2000).

\section{Assessment of fecundity of T. bactrae}

To determine the number eggs laid by a female parasitoid in its lifetime (fecundity), newly emerged female parasitoids were held singly in separate plastic vial $(2.5 \mathrm{~cm}$ dia. and $5.5 \mathrm{~cm}$ height) containing 80, one day old C. cephalonica eggs, prepared as an egg card. A drop of undiluted bees honey was placed on the inner surface of the lid of each vial. Vials were held at room temperature. After every $24 \mathrm{~h}$, parasitized egg card were replaced with fresh egg cards bearing $80 \mathrm{C}$. cephalonica eggs. This procedure was continued until no oviposition was observed. The parasitized egg cards were observed daily and number of parasitized eggs (those turned black) was counted. Twenty five females were used in this experiment.

\section{Assessment of longevity of $T$. bactrae}

To determine the longevity of $T$. bactrae, newly emerged 100 adult parasitoids were held singly in clear vials. Adults were fed with $50 \%$ diluted bees honey on a filter paper. Vials were maintained at room temperature $\left(28^{\circ} \mathrm{C}\right)$ and examined daily for dead insects. Dead insects were removed and a count was made. 


\section{Effect of parasitization capacities of $T$. bactrae with varying generations of $C$.} cephalonica eggs

It has been reported that egg parasitoids loose their egg laying capacity when they are reared continuously on alternative host eggs. Relevance of this effect for $T$. bactrae was investigated. Newly emerged (one day old) female parasitoids were placed singly in separate plastic vials $(2.5 \mathrm{~cm}$ dia. and $5.5 \mathrm{~cm}$ height) containing a one day old egg card of $C$. cephalonica. Each egg card had 100 C. cephalonica eggs. Undiluted bees honey was provided as food. The experiment was replicated with nine female parasitoids. After five days, number of parasitized eggs was counted. One day old adult females that emerged from parasitized eggs were held with a one day old C. cephalonica egg card and the number of parasitized eggs was counted. The Same procedure was followed for fifteen generations. Mean parasitism level was evaluated for each generation.

\section{Acceptance of cold-stored $C$. cephalonica eggs for parasitization by $T$. bactrae}

In mass rearing, when there is an oversupply of eggs, it is useful to store excess eggs for later parasitization. Suitability of such eggs was tested by storing C. cephalonica eggs at 4 and 8 ${ }^{\circ} \mathrm{C}$ for different durations: 1, 3, 7, 10, 20,30, and 40 days and exposing the eggs for parasitization by T. bactrae. Acceptance of host eggs was evaluated in terms of level of parasitism by $T$. bactrae. The methodology followed was adapted from Nadeem et al. (2010).

\section{Effect of storage of parasitized eggs at low temperature on emergence of $T$. bactrae}

To examine the effect of storing parasitized eggs, 2,500 C. cephalonica eggs parasitized by $T$. bactrae were held at 4 and $8^{\circ} \mathrm{C}$ for different durations and examined the adult emergence. Egg-cards $(1 \times 2 \mathrm{~cm})$, bearing 60 eggs per card, held for 1, 3, 7, 10, 30, 40, 50 and 60 days in storage $\left(4\right.$ and $\left.8{ }^{\circ} \mathrm{C}\right)$ were held for at room temperature for emergence of adults. Numbers of parasitoids emerged were counted and recorded.

\section{Dispersal ability of $T$. bactrae}

To determine the dispersal ability of parasitoid, the method of Ayvaz et al. (2008) was adopted. In a plant house, potted rice plants were arranged to simulate the plant arrangements in a rice field. Egg cards having $C$. cephalonica eggs were placed in concentric cycles at distances of $0,5,25,50,75,100,125,150 \mathrm{~cm}$. Only one circle was used at a time, starting from 0 and continued up to $150 \mathrm{~cm}$.

The same experimental procedure was used to examine the relationship between dispersal and released parasitoid density. A similar plant set up was used and the egg cards were placed in a circle of $150 \mathrm{~cm}$ radius, and the level of parasitism in relation to release rates was assessed.

The data from above experiments were analyzed using Chi square tests when data were non parametric and ANOVA was used for parametric data with SYSTAT Ver. 11. 


\section{RESULTS AND DISCUSSION}

\section{Assessment of the fecundity of T. bactrae}

Trichogrammatoidea bactrae oviposited over a period of five days, at a decreasing rate. The rate of oviposition significantly varied with the age of the parasitoids. One day old parasitoids had the highest oviposition rate (31.25 eggs per female per day), and it was 56.05 $\%$ of total fecundity. The mean number of eggs from second to fifth day was $13.5 \pm 0.5$, $7.9 \pm 0.6,2.9 \pm 0.3$ and $0.4 \pm 0.2$ respectively. These represent $24,14,5$ and $0.7 \%$ of the total fecundity. These findings agree with Naranjo (1993) who reported that T. bactrae has higher rate of oviposition very early in its adult life. Presence of relatively higher rate of oviposition among newly emerged females on release is a significant positive feature of a successful biological control agent. In addition, this feature is of convenience in mass rearing. Mean fecundity of $T$. bactrae was 55.75 eggs per female. Our findings on mean fecundity of $T$. bactrae were similar (55 eggs per female) to those of Naranjo (1993). Fecundity of $T$. bactrae could change with the type of host eggs. Fecundity of T. bactrae was 48.9 eggs/female when T. absoluta was used and 39 when $S$. cereallela was used as the host (Virgala and Botto, 2010). T. bactrae shows lower fecundity compared with other trichogrammatid egg parasitoid species. Trichogramma chilonis and T. ostriniae show a fecundity 135.6 and 117.5 eggs per female at $28^{\circ} \mathrm{C}$ (Hirashima et al., 1990). Trichogramma minutum lays 236.8 eggs per female at $25^{\circ} \mathrm{C}$ when Cydia pomonella, the natural host is used (Yu et al., 1984).

\section{Assessment of the longevity of T. bactrae}

The longevity of $T$. bactrae varied from 1-15 days with mean longevity of $7.9 \pm 0.37$ days, when fed on $50 \%$ bees honey. Longevity was 6.2 on T. absoluta and $6.1 \mathrm{~d}$ on S. cerealla (Virgala and Botto, 2010). Longevity of $T$. bactrae is comparatively shorter than in other egg parasitoid species. Trichogramma minutum adults have longevity of $28.5 \pm 5.4$ days when fed on $40 \%$ bees honey (Leatemia et al., 1995). This difference may be associated with the species used or environmental conditions under which experiments were conducted. However, effect of longevity appears to be less in T. bactrae because it lays $56 \%$ of its egg load within the first day when hosts eggs are provided. On the other hand, high longevity provides an opportunity to the adult female to select the most suitable eggs for laying eggs which has an effect on the biological fitness of the offspring.

\section{Effect of parasitization capacities of $T$. bactrae with varying generations of $C$. cephalonica eggs}

There was a significant variation $(\mathrm{F}=5.26 \mathrm{df}=14 ; 89 \mathrm{P}<0.001)$ in the level of parasitism with increasing generations, on the progeny numbers. The ability for parasitization in $T$. bactrae was reduced when the progeny continued on alternative hosts (Bueno et al., 2006). For some unexplainable reason, level of parasitism recorded in generation one was low (35.5\%). Some parasitoids did not oviposite at all. On exclusion of those, a significant variation in parasitism was recorded with increasing generations (Figure 1). Parasitism levels steadily decreased from 66 to $35 \%, 2^{\text {nd }}$ to $15^{\text {th }}$ generations. Similar results on parasitism have been reported by Hopper et al. (1993) and it was thought to be associated with genetic changes in the colony or adaptation to lab conditions. 


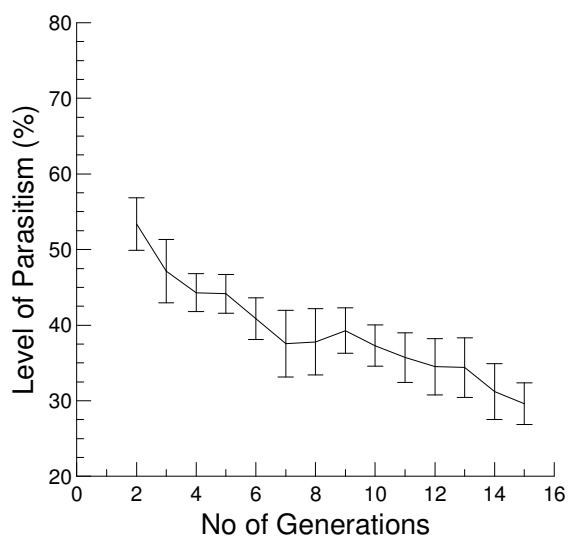

Fig. 1. Variation in level of parasitism in T. bactrae with number of generations when reared on $C$. cephalonica eggs, under laboratory conditions.

Certain other egg parasitoids have shown a much higher potential for rearing on alternate host over many generations without losing the quality: level of parasitization, sex ratio, and longevity. Bueno et al. (2006) reported that Trichogramma pretiosum when reared on Anagasta kuehniella eggs over 100 generations were not affected until the $20^{\text {th }}$ generation. The quality of $T$. pretiosum can be reestablished using the natural host even after $70^{\text {th }}$ generations. In this study, T. bactrae regained the former quality when it was reared on the natural host, $C$. medinalis. Quality of the egg parasitoids is very important as it affects its efficacy of suppressing the pest population. On the other hand, ability to mass rear while keeping the quality is important, especially, when it is intended to be used in augmentation and release programmes.

\section{Acceptance of cold-stored $C$. cephalonica eggs for parasitization by $T$. bactrae}

Level of acceptance of host eggs significantly varied with temperature $(\mathrm{F}=187 \mathrm{df}=1 ; 126$ $\mathrm{P}<0.001)$ and duration of storage $(\mathrm{F}=385 ; \mathrm{df}=6 ; 126 ; \mathrm{P}<0.001)$. In addition, the interaction of temperature $\mathrm{x}$ duration $(\mathrm{F}=2.3 ; \mathrm{df}=6 ; 126 ; \mathrm{P}=0.035)$ was not significant at $1 \%$. Overall, acceptance of $C$. cephalonica eggs stored durations significantly varied with temperature $(\mathrm{F}=10.5 ; \mathrm{df}=1 ; 138 ; \mathrm{P}<0.001)$. At $8{ }^{\circ} \mathrm{C}$, mean acceptance of host eggs was $41.5 \pm 2.4$ and $30.1 \pm 2.4$ at $4{ }^{\circ} \mathrm{C}$. Overall acceptance of $C$. cephalonica eggs stored at 4 and $8{ }^{\circ} \mathrm{C}$, significantly varied with the storage duration $(\mathrm{F}=156.3 ; \mathrm{df}=6 ; 133 ; \mathrm{P}<0.001)$. Level of acceptance steadily decreased with the increasing storage duration (Figure 2). 


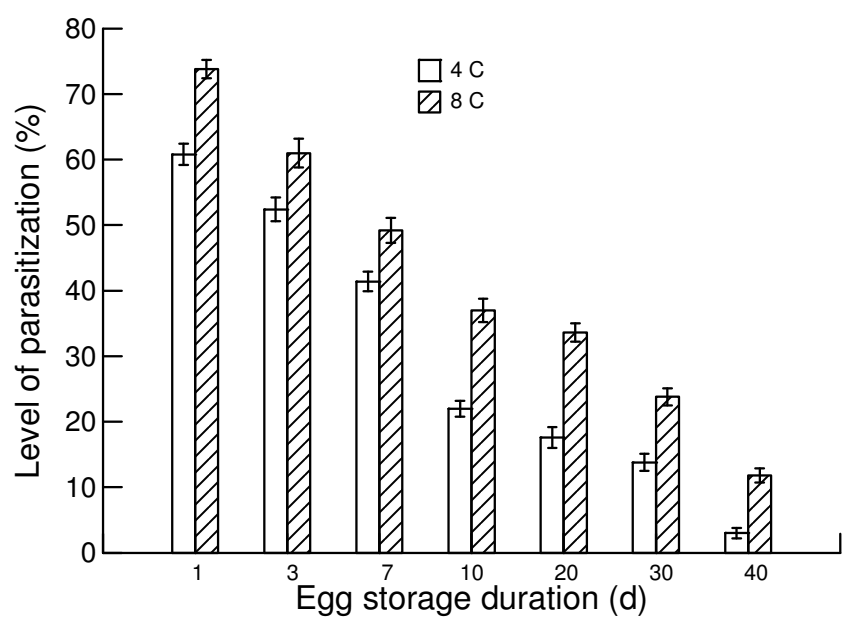

Fig. 2. Parasitization of Cocyra cephalonica eggs by $T$. bactrae following storage at $4^{\circ} \mathrm{C}$ and $8^{\circ} \mathrm{C}$ for different durations.

Clain et al. (2008) reported that T. chilonis accepted stored eggs for 9 weeks for parasitization and they recommend storing eggs up to $7^{\text {th }}$ week during mass rearing of $T$. chilonis. Acceptance of cold storage eggs is important to meet the fluctuating demand for adult parasitoids in biocontrol programmes.

\section{Effect of storage durations of parasitized eggs at low temperature on emergence of T. bactrae}

Parasitized eggs were stored at low temperatures in order to extend the shelf-life of the parasitized eggs. This is particularly important when the demand for parasitoids is variable. The level of parasitoid emergence significantly varied with storage temperature $(\mathrm{F}=24.5$; $\mathrm{df}=1 ; 56 ; \mathrm{P}<0.001)$ and duration $(\mathrm{F}=140.7 ; \mathrm{df}=6 ; 56 ; \mathrm{P}<0.001)$. The interaction of temperature and duration $(\mathrm{F}=0.859 ; \mathrm{df}=6 ; 56 ; \mathrm{P}=0.531)$ was not significantly different.

Parasitoid emergence of across all egg storage durations at $4{ }^{\circ} \mathrm{C}$ was $37.6 \pm 2.3 \%$ while that of at $8{ }^{\circ} \mathrm{C}$ was $41.9 \pm 2.2$. Parasitoid emergence significantly varied with different egg storage durations and across the two storage temperatures $(\mathrm{F}=103.5 ; \mathrm{df}=6 ; 63 ; \mathrm{P}<0.001)$. The highest adult emergence was recorded from one day of storage $(53.8 \pm 1.9 \%)$ at $8{ }^{\circ} \mathrm{C}$ and the lowest at $40 \mathrm{~d}$ storage $(9.8 \pm 0.9 \%)$ at $4{ }^{\circ} \mathrm{C}$. When adult emergence was considered separately for temperatures 4 and $8{ }^{\circ} \mathrm{C}$, it was steadily decrease with increasing stored durations (Figure 3 ). 


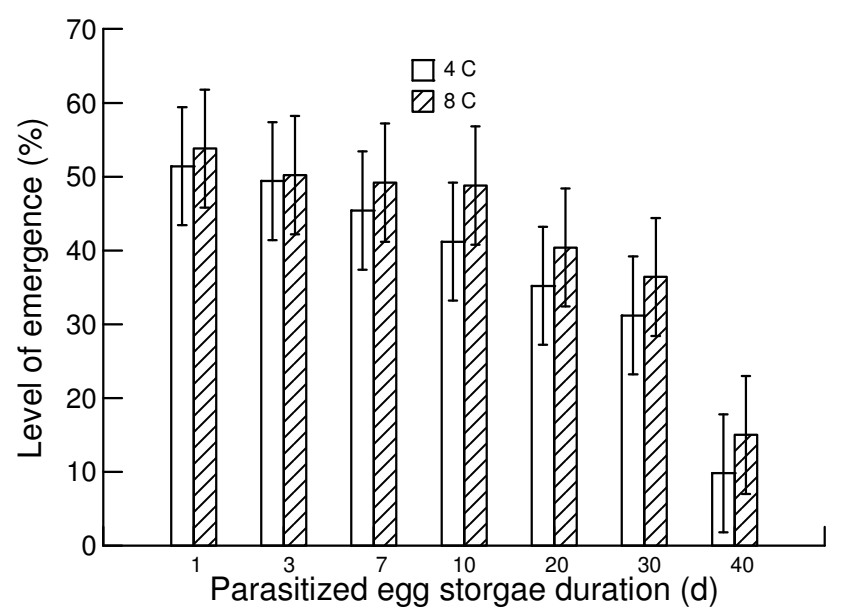

Fig. 3. Emergence of T. bactrae adults from parasitized Cocyra eggs stored at 4 and $8^{\circ} \mathrm{C}$, for different durations.

Kumar et al. (2005) have conducted a similar study and found that adult emergence of trichogrammatids was very high $(95.6 \%)$ after one day of storage. Similar results have been obtained for other egg parasitoid species. Eggs parasitized by T. chilonis can be stored up to 30 days without a loss in emergence rate (72.4\%) (Pathak et al., 2010). Similarly, eggs parasitized by Anaphes iole Girault (Hymenoptera: Mymaridae) can be stored up to 20 days at $10{ }^{\circ} \mathrm{C}$ when parasitoids are at the pupal stage within the host eggs (Abdullah et al., 2009; Ramos and Cate, 1992).

\section{Dispersal ability of $T$. bactrae}

C. cephalonica eggs placed at different distance were parasitized and the level of parasitism varied significantly with the distance $(\mathrm{F}=1623 ; \mathrm{df}=7 ; 792 ; \mathrm{p}<0.001)$. T. Bactrae successfully reached $25 \mathrm{~cm}$ distance but the number reaching beyond $25 \mathrm{~cm}$ was significantly dropped. However, even the egg cards kept at $150 \mathrm{~cm}$ from point of release had been parasitized, indicating that few insects were capable of reaching $150 \mathrm{~cm}$ distance (Figure 4).

When a higher number of parasitoids were released, increasing numbers of insects dispersed over long distance. When egg cards were kept at a distance of $150 \mathrm{~cm}$, over $80 \%$ of host eggs were parasitized upon the release of 140 egg parasitoids. Findings of these two experiments indicated that parasitoids dispersal is dose dependent (Figure 4 and 5) phenomenon. This idea is in agreement with Ayvaz et al. (2008), who reported that, when 1,000 Trichogramma evanescens were released, parasitism of host eggs was $11.41 \%$, which increased to $29.75 \%$ and $62.06 \%$ when 2000 and 3000 parasitoids were released respectively. 



Fig. 4. Dispersal distance of T. bactrae in Fig. 5. Release rate of parasitoids and experimental arena and level of parasitism of host eggs level of parasitism of host eggs cards at $150 \mathrm{~cm}$ radius circle in a simulated rice field.

\section{CONCLUSIONS}

On the average Trichogrammatoidea bactrae lives $7.9 \pm 0.37$ days and lays 55 eggs/female over 5 days, depositing $56 \%$ of egg load within the first day. T. bactrae parasitized $C$. cephalonica eggs stored at low temperature $\left(4\right.$ and $\left.8{ }^{\circ} \mathrm{C}\right)$ and parasitized eggs also can be stored at low temperature resulting in successful parasitoid emergence. These characters of $T$. bactrae are conducive for mass rearing. Hence, it can be concluded that $T$. bactrae can be easily mass cultured which is an essential feature of a biocontrol agent. T. bactrae is also capable of dispersing over $150 \mathrm{~cm}$. In order to parasitize host eggs within $150 \mathrm{~cm}$ radius releasing, 150 parasitoids are required to achieve $>80 \%$ parasitism. Based on these findings, it can be concluded that $T$. bactrae is a promising candidate to be used as an effective biocontrol agent in augmentation releases in the management of rice leaf folder.

\section{ACKNOLEDGEMENT}

National Research Council (NRC) of Sri Lanka is acknowledged for financial assistance (Grant No: 11-116).

\section{REFERENCES}

Abdullah, K., Ellington, J.J., Yasmin, S. (2009). Storage studies of Anaphes iole Girault (Hymenoptera: Mymaridae) at different developmental stages, temperatures and light-dark regimes. Agriculturae Conspectus Scientificus (Poljoprivredna Znanstvena Smotra) 74, 319 326.

Ayvaz, A., Karasu, E., Karabörklü, S. and Yilmaz, S. (2008). Dispersal ability and parasitization performance of egg parasitoid Trichogramma evanescens Westwood (Hymenoptera: Trichogrammatidae) in field and storage conditions. Turk. J. Biol. 32, 127133. 
Barrion, A.T. and Litsinger, J.A. (1994). Taxonomy of rice insect pests and their arthropod parasites and predators. In: Heinrichs, E.A. (ed.) Biology and management of rice insects. Wiley Eastern Limited, New Delhi.

Bueno, R.C.O. de F., Bueno, A. de F., Pratissoli, D., Vieira, S.S., Oliveira, L.J., Barros, E.M. and Jakoby, G.L. (2006). Biological characteristics of Trichogramma pretiosum (Riley, 1879) reared on Anagasta kuehniella (Zeller, 1879) for 100 generations. Ecossistema, 31: 69 -75 .

Clain, C., Roux, E., Dubois, A., Goebel, R. and Tabone, E. (2008) Evaluation of cold-stored eggs of Ephestia küehniella Zeller (Lepidoptera: Pyralidae) for parasitization by Trichogramma chilonis Ishii (Hymenoptera: Trichogrammatidae). Association Française de Protection des Plantes (AFPP), Alfortville, France, AFPP - 8ème Conférence Internationale sur les Ravageurs en Agriculture, Montpellier SupAgro, France, 22-23 Octobre 2008: 417426.

Eliopoulos, P.A., Stathas, G.J. and Bouras, S.L. (2005). Effects and interactions of temperature, host deprivation and adult feeding on the longevity of the parasitoid Venturia canescens (Hymenoptera: Ichneumonidae). Eur. J. Entomol. 102, 181 - 187.

Hemachandra, K.S., Polaszek, A. and Perera, M.C.D. (2014). Egg parasitoids of Cnaphalocrocis medinalis (Guenee): the first record of Trichogrammatoidea bactrae Nagaraja and Trichogrammatoidea nana Zehntner (Hymenoptera: Trichogrammatidae) in Sri Lanka. First Ruhuna International Science and Technology Conference 1: 19.

Heong, K.L., Teng, P.S. and Moody, K. (1995). Managing rice pests with less chemicals. Geo Journal 35(3), 337 - 349

Hopper, K.R., Roush, R.T. and Powell, W. (1993). Management of genetics of biologicalcontrol introductions. Ann. Rev. Entomol. 38, 27 - 51.

Hirashima, Y., Miura, K., Miura, T. and Hasegawa, T. (1990). Studies on the biological control of the diamondback moth, Plutella xylostella (Linnaeus). Effect of temperature on the development of the egg parasitoids Trichogramma chilonis and Trichogramma ostriniae. Kyushu Univ., Sci. Bull. Fac. Agric. 44, 81 - 87.

Kumar, P., Shenhmar, M. and Brar, K.S. (2005). Effect of low temperature storage on the efficiency of three species of trichogrammatids. Bio. Control 19(1), 17 - 22.

Lawler, S.P, (2001). Rice fields as temporary wetlands: a review. Israel J. Zool. 47(4), 513 528.

Leatemia, J.A., Laing, J.E. and Corrigan, J.E. (1995). Effects of adult nutrition on longevity, fecundity and offspring sex ratio of Trichogramma minutum Riley (Hymenoptera: Trichogrammatidae). Can. Entomol. 127, 245 - 254.

Nadeem, S., Ashfaq, M., Hamed, M. and Ahmed, S. (2010). Optimization of short and long term storage duration for Trichogramma chilonis (Ishii) (Hymenoptera: Trichogrammatidae) at low temperatures. Pakistan J. Zool. 42(1), 63 - 67. 
Nagaraja, H. (1978). Studies on Trichogramma (Hymenoptera: Trichogrammatidae). Oriental Insects. 12 (4), 489 - 530.

Naranjo, S.E. (1993). Life history of Trichogrammatoidea bactrae (Hymenoptera: Trichogrammatidae), an egg parasitoid of pink bollworm (Lepidoptera: Gelechiidae), with emphasis on performance at high temperatures. Environ. Entomol. 22, 1051 - 1059.

Nathan, S.S., Kalaivani, K., Manikam, R.W. and Murugan, K. (2006) Effects of millet, wheat, rice and sorghum diets on development of Cocyra cephalonica (Stainten) (Lepidoptera: Galleriidae) and its suitability as a host for Trichogramma chilonis Ishii (Hymenoptera: Trichogrammatidae). Environ. Entomol. 35, 784 - 788.

Nugaliyadde, L., Dissanayake, N. and Mitrasena, J. (2000). Advance in pest and disease management of rice in Sri Lanka: a review. ASDA 2, $409-422$.

Ooi, P.A.C. and Shepard, B.M. (1994). Predators and parasitoids of rice insect pests. pp. 585-612. In: Heinrichs, E.A. (Ed.) Biology and management of rice insects. Wiley Eastern Limited, New Delhi.

Pathak, S.K., Dubey, M.N., Yadav, P.R. and Yadav, P.R. (2010) Suitability of temperature for the storage of Trichogramma chilonis. J. Exp. Zool. 13, 53 - 55.

Ramos, J.A.M. and Cate, J.R. (1992). Rate of increase and adult longevity of Catolaccus grandis (Burks) (Hymenoptera: Pteromalidae) in the laboratory of four temperatures. Environ. Entomol. 21, 620 - 627.

Ranasinghe, M.A.S.K. (1992). Paddy pests in Sri Lanka. Natural Resource Energy and Science Authority, 47/5 Maitland place, Colombo 07, Sri Lanka. pp 43-44.

Roger, P.A., Heong, K.L. and Teng, P.S. (1991). Biodiversity and sustainability of wetland rice production: role and potential of microorganisms and invertebrates, pp 117-136. In: Hawksworth, D.L. (ed.), The biodiversity of microorganisms and invertebrates: its role in sustainable agriculture. CAB International, Wallingford, UK.

Sreekumar, K.M. and Paul, A.V.N. (2000). Labour efficient technology for the mass production of rice meal moth Corcyra cephalonica. Indian J. Entomol. 62(3), 304 - 311.

Virgala, M.B.R.; Botto, E.N. (2010). Biological studies on Trichogrammatoidea bactrae Nagaraja (Hymenoptera: Trichogrammatidae), egg parasitoid of Tuta absoluta Meyrick (Lepidoptera: Gelechiidae). Neotropical Entomology 39(4), 612 - 617.

Yu, D.S., Laing, J.E. and Hagley, E.A.C. (1984). Dispersal of Trichogramma spp. (Hymenoptera: Trichogrammatidae) in an apple orchard after inundative releases. Environ. Entomol. 13, 371 - 374. 